\title{
Hypnosis Associated with 3D Immersive Virtual Reality Technology in the Management of Pain: A Review of the Literature
}

This article was published in the following Dove Press journal: Journal of Pain Research

\author{
Floriane Rousseaux ${ }^{1-3}$ \\ Aminata Bicego ${ }^{1-3}$ \\ Didier Ledoux ${ }^{3,4}$ \\ Paul Massion ${ }^{4}$ \\ Anne-Sophie Nyssen ${ }^{1,3}$ \\ Marie- \\ Elisabeth Faymonville ${ }^{2}$ \\ Steven Laureys iD $^{5}$ \\ Audrey Vanhaudenhuyse ${ }^{2,3}$ \\ 'Laboratory of Cognitive Ergonomics and \\ Work Intervention, University of Liège, \\ Liège, Belgium; ${ }^{2}$ Algology Department, \\ University Hospital of Liège, Liège, \\ Belgium; ${ }^{3}$ Sensation \& Perception \\ Research Group, GIGA Consciousness, \\ University of Liège, Liège, Belgium; \\ ${ }^{4}$ Intensive Care Units, University Hospital \\ of Liège, Liège, Belgium; ${ }^{5} \mathrm{GIGA}$ \\ Consciousness, University of Liège, Liège, \\ Belgium
}

Correspondence: Floriane Rousseaux Sensation \& Perception Research Group, GIGA Consciousness, Domaine Universitaire du Sart Tilman, B35, Liege B4000, Belgium

Tel + 3243663462

Email floriane.rousseaux@uliege.be

Audrey Vanhaudenhuyse

Algology Department and Sensation \&

Perception Research Group, GIGA

Consciousness, Domaine Universitaire du

Sart Tilman, B35, Liege B4000, Belgium

$\mathrm{Tel}+3243668033$

Email avanhaudenhuyse@chuliege.be

\begin{abstract}
Hypnosis is well documented in the literature in the management of acute and chronic pain. Virtual reality (VR) is currently gaining credibility in the same fields as hypnosis for medical applications. Lately, the combination of hypnosis and VR was considered. The aim of this scoping review is to understand the current studied contexts and effects of virtual reality hypnosis (VRH) for the management of pain. We searched on PubMed, Taylor \& Francis Online, and ProQuest databases with the following terms: "virtual reality," "3D," "hypnosis," and "pain". We included 8 studies that combined hypnosis and VR. All articles are in English. Two included healthy volunteers and six are clinical studies. Short-term results indicated significant decreases in pain intensity, pain unpleasantness, time spent thinking about pain, anxiety, and levels of opioids. However, results are not consistent for all patients all the days. VR alone seems to reduce pain independently of the hypnotizability level. One study claimed that VR and hypnosis could alter each other's effects and another argued that VR did not inhibit the hypnotic process and may even facilitate it by employing visual imagery. We cannot affirm that VR added value to hypnosis when they are combined. These trials and case series gave us indications about the possible applications of VRH in different contexts. Additional randomized clinical trials on VRH in the future will have to test this technique in clinical practice and help define guidelines for VRH utilization in pain management.
\end{abstract}

Keywords: hypnosis, virtual reality, 3D animation, virtual reality hypnosis, acute pain, chronic pain

\section{Introduction}

Alleviating patients' suffering and pain remains an important challenge in medicine. Different non-pharmacological techniques are currently being used as complementary tools in the treatment of acute and chronic pain, including cognitive-behavioral therapies, biofeedback, acceptance-based approaches, hypnosis, and virtual reality (VR). ${ }^{1-5}$ A new technique that combines hypnosis and VR, called "virtual reality hypnosis" (VRH), is increasingly being studied although its actual effectiveness remains unknown. The purpose of this review is to understand the current knowledge regarding the application of $\mathrm{VRH}$ in the management of acute and chronic pain. First, we briefly describe acute and chronic pain. Second, we discuss several applications of hypnosis alone and VR alone in the management of pain. Third, we review studies based on the combination of VR and hypnosis to define its potential for action in pain modulation. 


\section{Acute and Chronic Pain: A Brief Description}

Pain is defined as "an unpleasant sensory and emotional experience associated with actual and potential tissue damage, or described in terms of such damage." 6 The phenomenon is comprised of a combination of sensations, emotions, behaviors, and cognitions. It is recognized that every physiological explanation of pain contains an implicit psychological concept that has a profound impact on both the study and treatment of pain itself. Acute pain is a protective sensation that we all must have to survive; it is an alarm signal that informs us about potential damage which may challenge our body's integrity. Pain-related processing results from the interaction of sensory and affective components, ie, interactions between sensory characteristics of the stimulus, the state of the nervous system based on past experiences, and on the cognitive and emotional processes of the organism at the time of sensory input. ${ }^{7,8}$ Sensory processes refer to the quality, intensity, and spatio-temporal characteristics of the pain sensation, while affective-motivational processes relate to its negative valence and averseness. ${ }^{9}$ Pain cerebral correlates are described in terms of neural circuits or networks, referred to as the "neuromatrix" for pain-related processing. ${ }^{10,11}$ Neuroimaging studies have presented evidence for two distinct cerebral networks involved in the perception of pain: the sensory (somatosensory thalamus, primary and secondary somatosensory cortices) and the affective pathways (medial thalamic nuclei, anterior cingulate, prefrontal and insular cortices). ${ }^{12}$ The tools for treating acute pain include cause removal, medication, regional analgesia, physical methods, and/or psychological approaches. Chronic pain is a complex phenomenon characterized by prolonged and persistent pain lasting at least 3 months, involving biological, psychosocial, and socioprofessional factors that affect patients and their social and family environments. No single medication or treatment addresses all aspects of this condition and chronic pain remains a financial public health problem. ${ }^{13}$ Patients and clinicians are increasingly turning to nonpharmacological treatments, specifically to new approaches based on the biopsychosocial model. For example, interventions based on music therapy, meditation, and hypnosis have shown promising positive results regarding diminution of pain perception, anxiety and depression, modification of coping strategies, and/or improvements to quality of life. ${ }^{14-17}$

\section{Hypnosis}

Hypnosis is defined as a "state of consciousness involving focused attention and reduced peripheral awareness, characterized by an enhanced capacity for response to suggestions." ${ }^{18}$ Hypnosis includes many cognitive and behavioral components that allow patients to use their mind to influence their own body sensations. ${ }^{19,20}$ An important feature of hypnosis is the individual's ability to experience suggested alterations in physiology, sensations, emotions, thoughts, or behavior (ie, hypnotizability). ${ }^{18}$ The effect of hypnosis has been described in various clinical settings. ${ }^{21-24}$ For example, since 1992, in Liege (Belgium), hypnosis has been used as an adjunct to slight conscious sedation to perform surgery with local anesthesia, called hypnosedation. Hypnosedation can be used in various surgical situations. ${ }^{22}$ This technique is associated with improved peri- and post-operative comfort, better conditions during the performance of surgery, reduced anxiety, emotional distress, pain, and nausea, as well as diminished intraoperative requirements for anxiolytic and analgesic drugs. ${ }^{22,25}$ Some authors also showed a faster recovery with a significant decrease in the delay before restarting professional activity. ${ }^{23}$ Other applications have shown that hypnosis combined with self-care learning have demonstrated benefits for chronic pain patients, in a variety of biological, psychological, and social dimensions (decreased pain intensity, pain interference, anxiety and depression, improved quality of life). ${ }^{16,17}$ Similar results were reported with oncological patients. ${ }^{26-28}$

\section{Virtual Reality}

VR technology offers new opportunities for clinical research and intervention by creating a human testing and training multi-sensory $3 \mathrm{D}$ dynamic environment. VR reality can be defined as

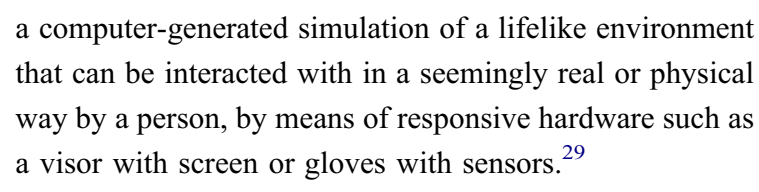

VR reality has been used in different clinical context such as physical therapy, acute and chronic pain management, clinical education, cognitive and motor rehabilitation, anxiety management, and communication skills training. ${ }^{5}$ Furthermore, VR can be interesting in addition to pharmacotherapy and analgesia in anxiety and pain reduction, 5,30 as an adjunct therapy for the management of acute pain in adults and children, ${ }^{31}$ and allows patients to alter the 
patient's attention, emotions, and concentration. ${ }^{32,33}$ Clinical studies exploring its use for chronic pain patients are limited, and the value of VR in chronic pain management can be an area of potentially high impact research. ${ }^{34}$ Some evidence were found for the short-term efficacy of VR, but no evidence was seen for persistent benefits, ${ }^{35}$ in contrast to the use of self-hypnosis which has already shown its efficacy for chronic pain patients after 9 months of regular practice. ${ }^{16,17}$ This is a reason to combine these tools together.

\section{Virtual Reality Hypnosis}

Although VR is now well-documented and commonly used in commercial fields, scientific, and clinical research; VR combined with hypnosis is far from being as widespread as the distractive version of VR reported in the literature. The interest in joining the two techniques in one therapy is to use a virtual $3 \mathrm{D}$ movie to immerse the patient as he/she is guided by hypnotic suggestions. VRH is defined as "a hypnotic induction and analgesic suggestion delivered by customized virtual reality (VR) hardware/software." 36 VRH was used to facilitate induction and suggestions in very few studies. ${ }^{37,38}$ Some authors believe that VRH could be more useful for low hypnotizable persons than traditional hypnosis because it easily focuses the attention even for those with lack imaginative capacities. $^{39}$ In contrast, traditional hypnosis typically involves eye closed self-generated imagery. However, it is possible that eyes open with rich visual information from VR might interfere with the participants' ability to achieve a hypnotized state. Nevertheless, the fundamental concepts and efficacy of clinical use of VRH are still not well documented in the literature. Our hypothesis is that VR could improve the benefits of hypnosis for pain management. To this end, the aim of this review is to give a broad descriptive overview about what already exists regarding $\mathrm{VRH}$ and pain.

\section{Methods}

One purpose of this scoping review is to give a general point of view of what already exists in the literature on the combination of two non-pharmacological techniques: virtual reality and hypnosis for the management of pain. We searched on PubMed, Taylor \& Francis Online, and ProQuest databases with the following terms: "virtual reality," “3D," "hypnosis," and "pain". Inclusion criteria: using hypnosis in live settings or by audiotape with VR total immersive headsets for the management of pain.
Hypnosis or verbal suggestions/posthypnotic suggestions can be used before/during/or after the VR session.

\section{Results}

We screened 598 articles and made a selection according to the titles and abstracts (Figure 1). We found 22 records and removed 5 of them according to their materials and protocols to keep articles with hypnosis and VR in combination. After this first selection, 17 articles from 2004 to 2018 about both hypnosis and VR were selected from which we removed 9: a protocol description for a future study, an abstract about 2D animation, a letter to the editors, and a 2D animation with augmented reality but not fully immersive VR, other articles were focused on autism, mood, brain mechanisms, and two on anxiety. We included 8 studies in this review that combined hypnosis and $3 \mathrm{D}$ VR in their protocol for pain management. All articles are in English. Five are case studies and three are randomized trials (Table 1).

\section{Studies Design}

The eight studies included in this review used the computer generated VR SnowWorld, which consists in a threedimensional ice canyon with penguins and snowmen. ${ }^{40}$ The distractive version of snow world is a fully immersive VR distraction where users have to punch throw snowballs with a click on the mouse and touch icemen and penguins to make them disappear. Patients can interact with the virtual world. The hypnotic version of SnowWorld takes off the joystick and the snowballs games and focuses on a voice that suggests going deeper into the canyon and feel more and more comfortable. Hypnosis was mostly made of suggestions about relaxation, analgesia or suggestions to increase the sense of presence in VR. Suggestions can

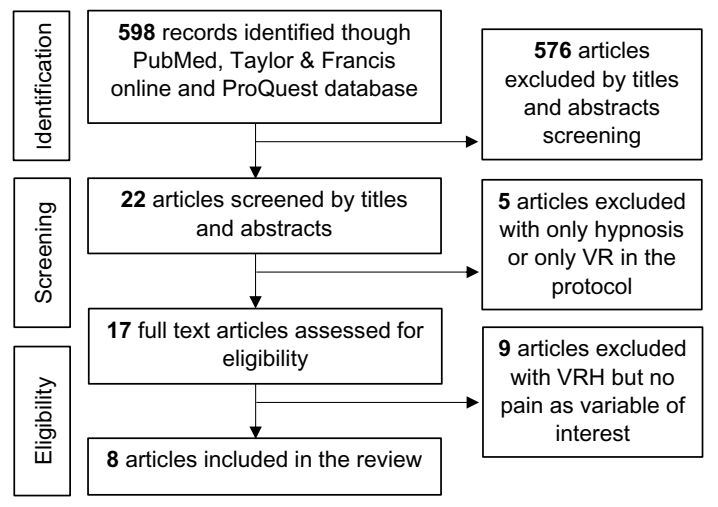

Figure I Flowchart of articles inclusion and exclusion. 


\begin{tabular}{|c|c|c|c|c|}
\hline 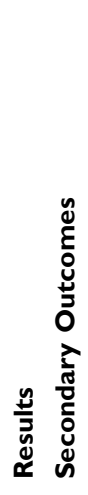 & 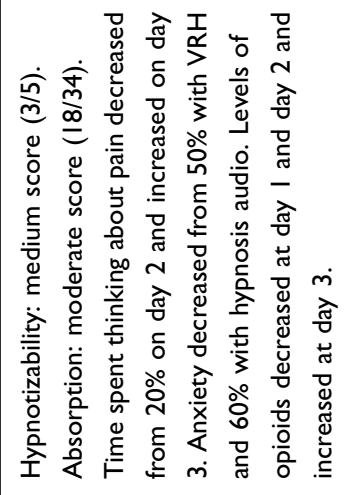 & 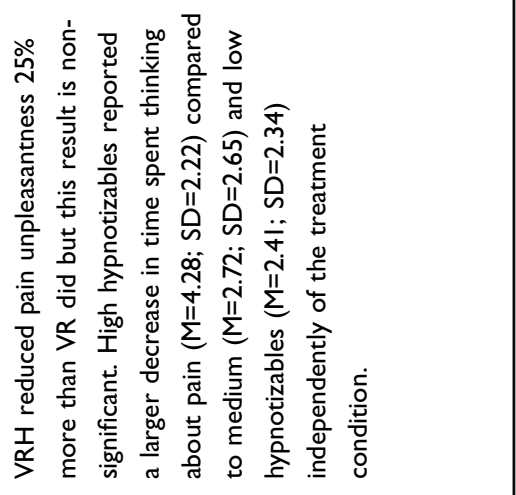 & 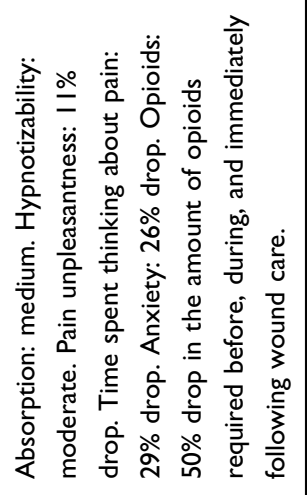 & 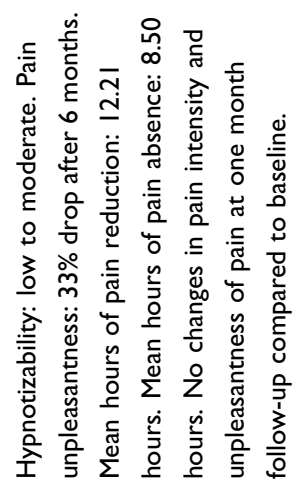 \\
\hline 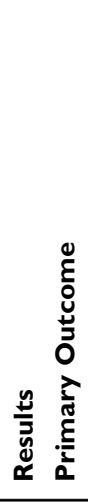 & 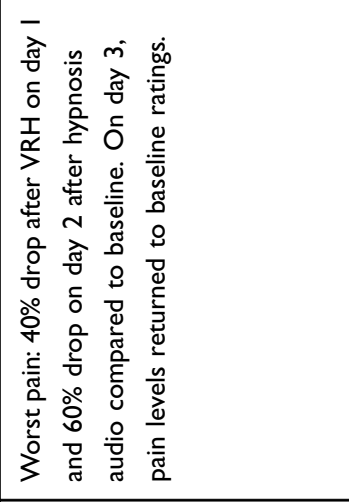 & 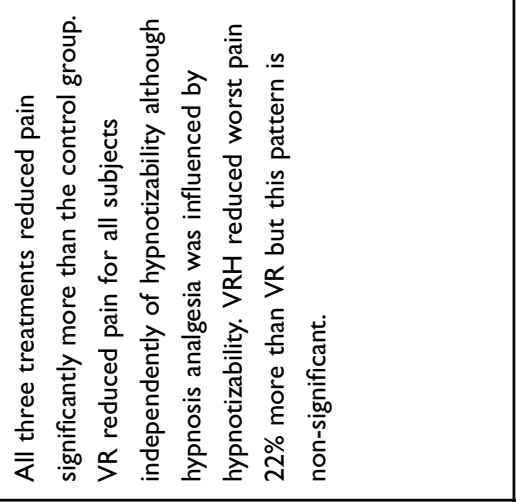 & 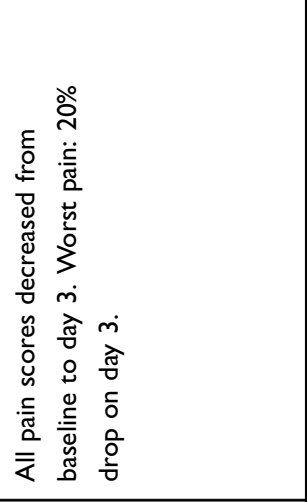 & 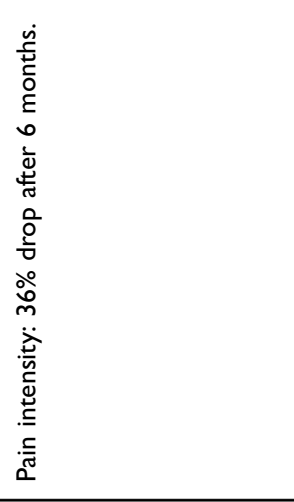 \\
\hline ڤ̆ & 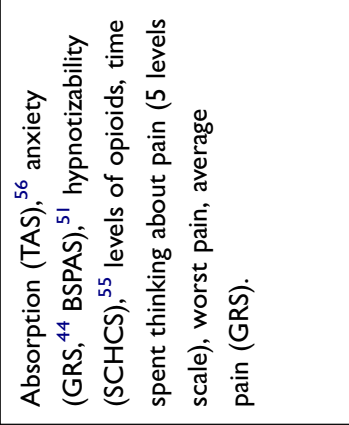 & 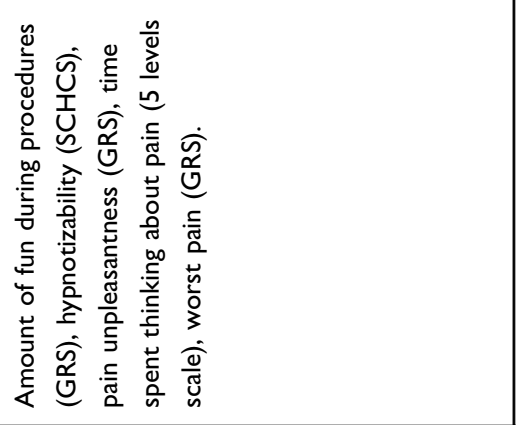 & 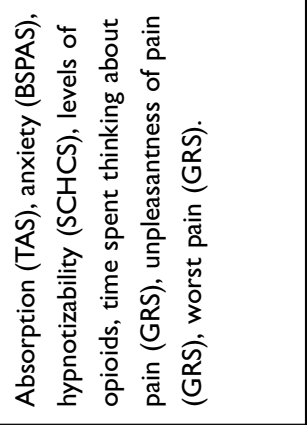 & 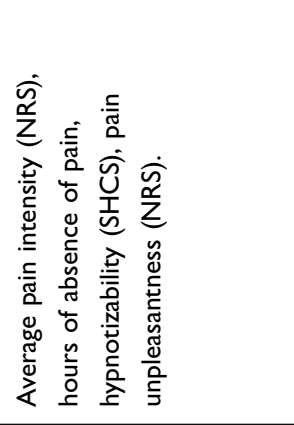 \\
\hline 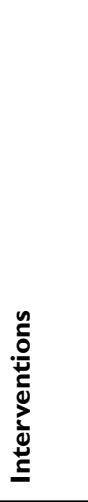 & 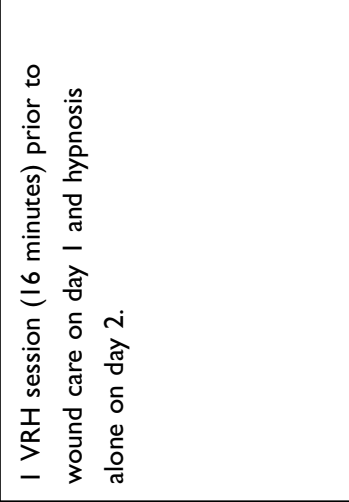 & 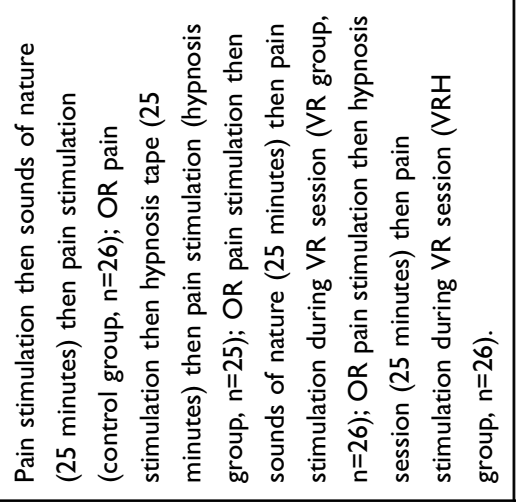 & 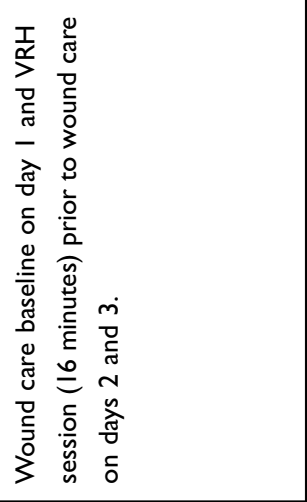 & 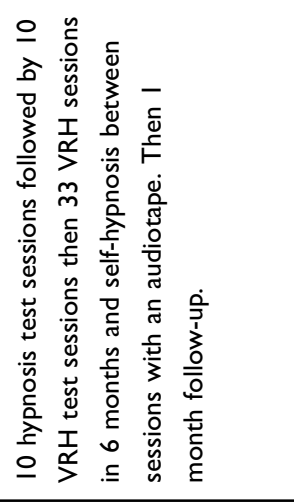 \\
\hline 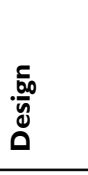 & 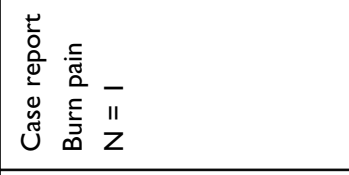 & 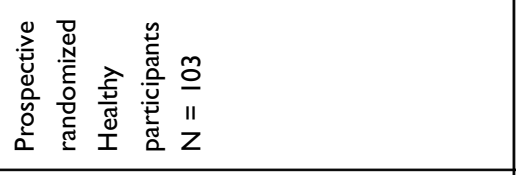 & 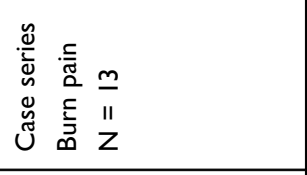 & 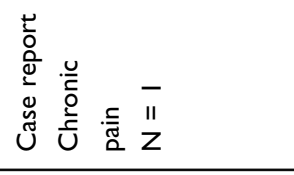 \\
\hline & 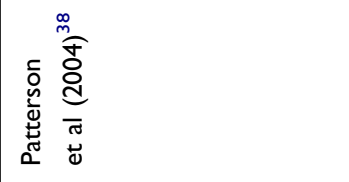 & 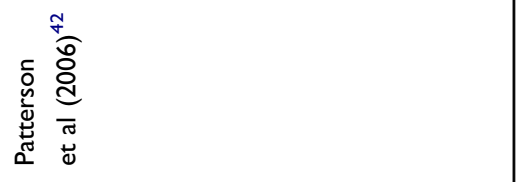 & 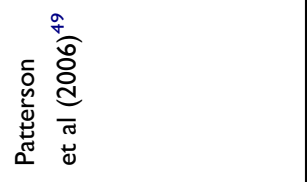 & 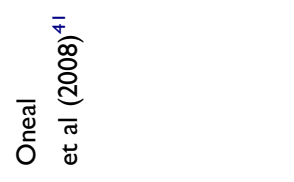 \\
\hline
\end{tabular}




\begin{tabular}{|c|c|c|c|}
\hline 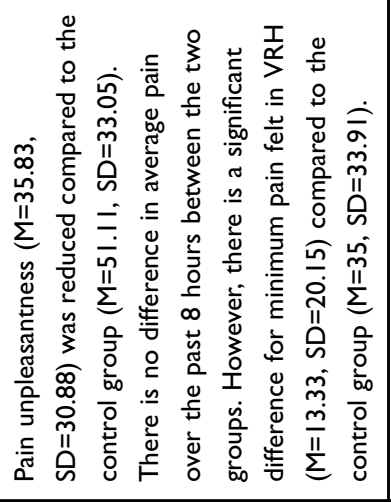 & 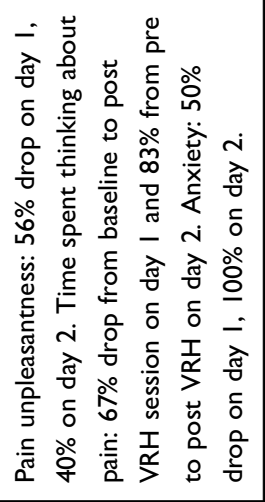 & 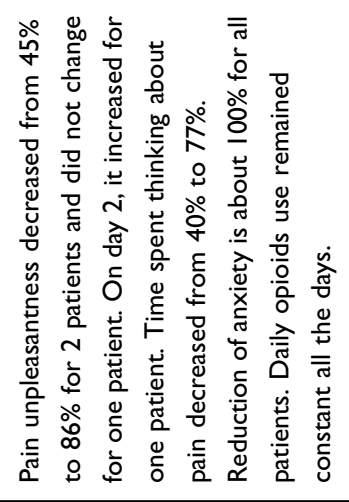 & 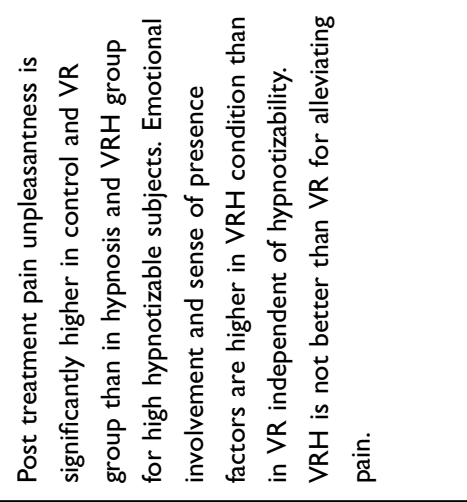 \\
\hline 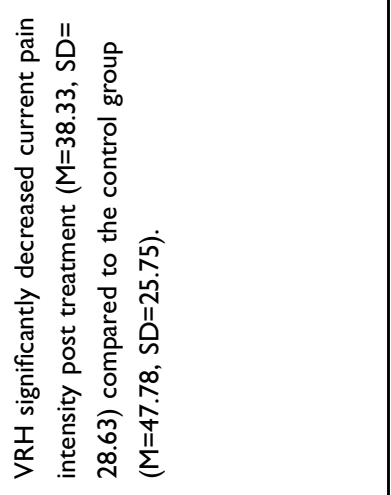 & 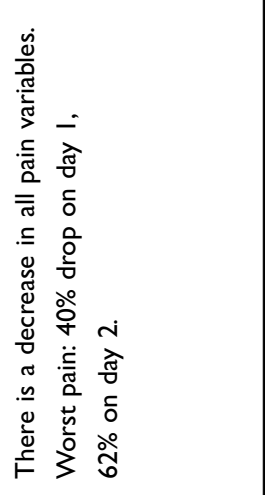 & 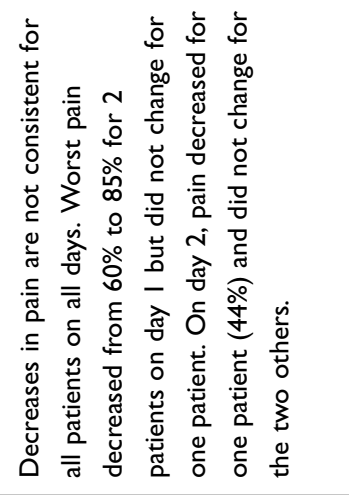 & 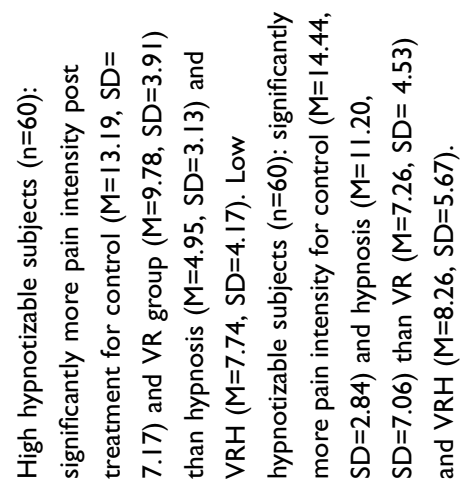 \\
\hline 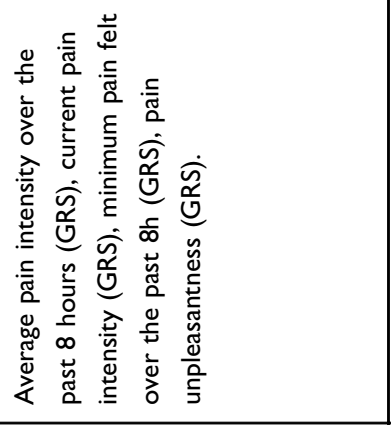 & 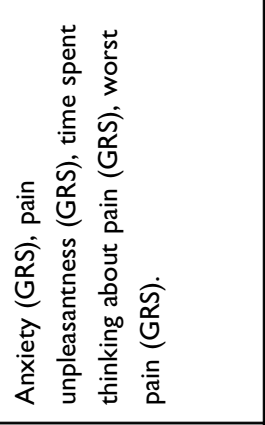 & 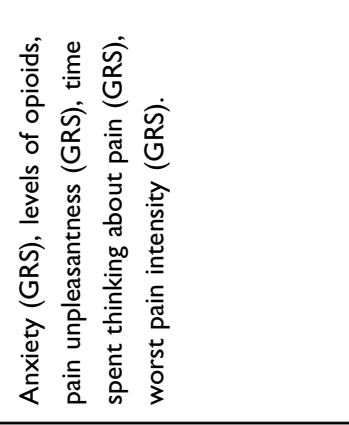 & 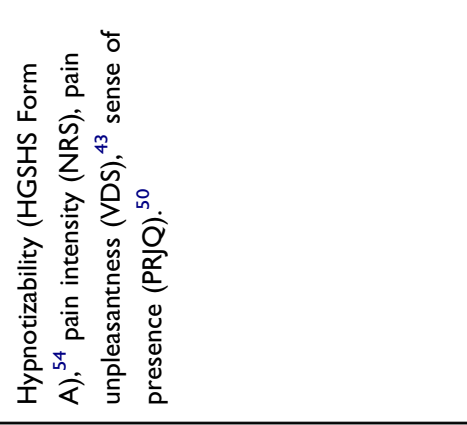 \\
\hline 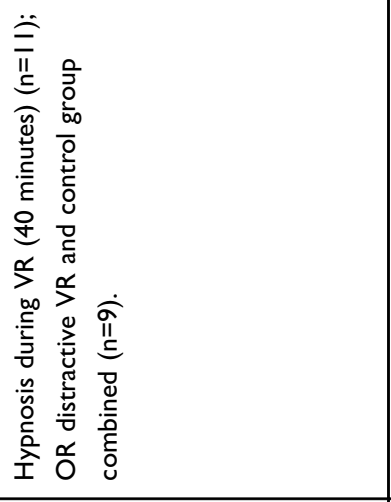 & 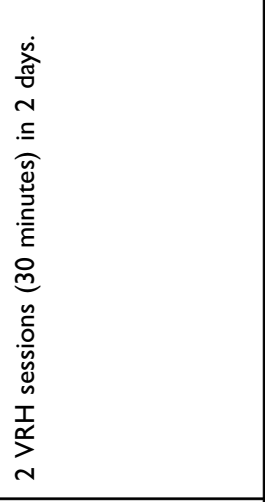 & 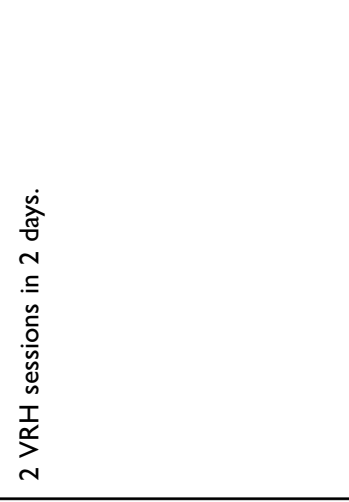 & 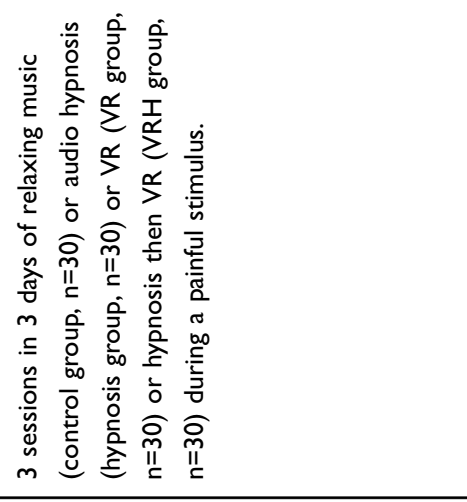 \\
\hline 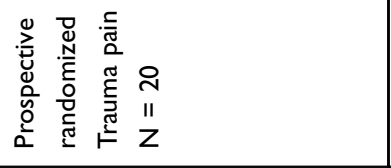 & 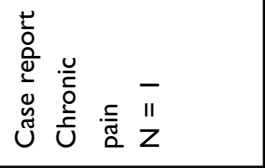 & 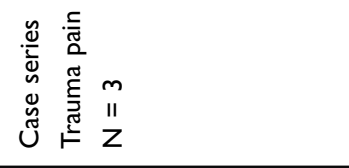 & 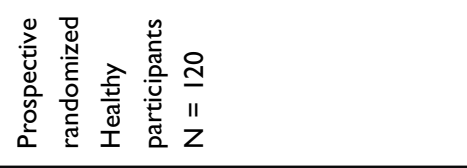 \\
\hline 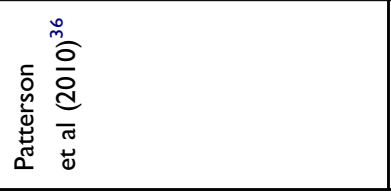 & 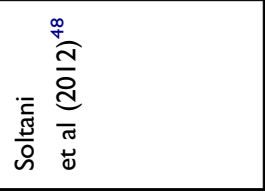 & 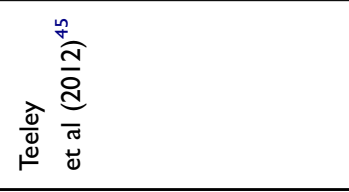 & 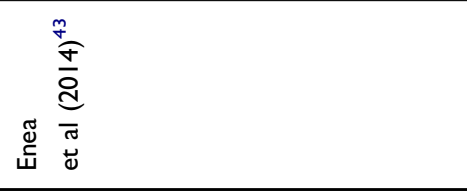 \\
\hline
\end{tabular}


be said directly by a therapist or patients can listen to a recorded audiotape. One study recommended to additionally practice self-hypnosis at home between sessions (without any VR). ${ }^{41}$ Regarding the design of studies, different ways of combining "VR" and "hypnosis," different moments of application, and variable durations of therapy exposure were used. VRH displays can integrate VR and hypnosis at the same time or at different times. Two studies used hypnosis prior to the VR. ${ }^{42,43}$ Number of VRH sessions varies from one to thirty-three according the studies.

\section{Pain as Main Outcome in VRH Studies Acute Pain}

Pain Intensity

Seven studies measured the subjective average pain intensity with a graphic rating scale (from 0 to 100$)^{44}$ and one study assessed pain every 20 seconds during a painful stimulus with a Numeric Rating Scale (from 0 to 10 ). ${ }^{43}$ A first case study with a severely burned patient showed a decrease in pain intensity from $40 \%$ on day 1 with VRH to $60 \%$ on day 2 with hypnosis audio alone. However, there is a limit to the effect on day 3 without VRH (patient's pain ratings returned almost to a baseline level on day 3). ${ }^{38} \mathrm{~A}$ case study series with three trauma patients showed that pain reduction rates (compared to baseline) varied from $44 \%$ to $85 \%$ when VRH was applied, but there was no consistent effect for all patients on all days. ${ }^{45}$ One study showed that VRH, VR alone and audio hypnosis alone significantly reduced pain (finger pressure) in healthy volunteers compared to control group. ${ }^{43}$ Interestingly, two studies have shown that VR alone reduced pain regardless of the participants' hypnotizability, whereas analgesia from hypnosis was mostly significant for highly hypnotizable subjects. ${ }^{42,43}$ For high hypnotizables, Patterson et al (2006) found a non-significant pattern that VRH reduced pain more effectively than VR alone. ${ }^{42}$ Authors suggested that hypnosis and VR involve different mechanisms. A trial in trauma patients showed that VRH reduced subjective perception of pain for patient 1 hour following intervention, compared to VR alone or no treatment. ${ }^{36}$

\section{Pain Unpleasantness}

Pain intensity and pain unpleasantness are two distinct concepts. ${ }^{42,46,47}$ From pre-test to post-VRH treatment, the amount of pain unpleasantness dropped by $11 \%$ to $44 \%$ according to the studies. A randomized study indicated that in 20 trauma patients the addition of VRH to standard care resulted in significant reduced pain unpleasantness at one hour following VRH, compared to standard care alone. $^{36}$ When mechanical pain (finger pressure) was applied in healthy volunteers, it appears that VR and VRH decreased pain unpleasantness more than in hypnosis or in control conditions for low hypnotizable subjects, and hypnosis and VRH decrease pain unpleasantness more than VR or control group for high hypnotizable subjects. ${ }^{43}$ Patterson et al (2006) highlighted the nonsignificant tendency that hypnosis combined with VR reduced pain unpleasantness more than VR alone (44\% vs $33 \%$ reduction, respectively). ${ }^{42}$

\section{Time Spent Thinking About Pain}

Five studies were interested in the rating of time spent thinking about pain (usually reported by patients with verbal descriptors such as none of the time, some of the time, half of the time, most of the time, and all of the time). Case report studies showed that the reduction in the amount of time when patients thought about their pain varied from $29 \%$ to $83 \%$ from baseline to VRH post-treatment depending on patients and days. ${ }^{45,48,49}$ In healthy volunteers, it seems that there was an effect of hypnotizability $(p<0.05)$, meaning that high hypnotizables reported a larger decrease in time spent thinking about pain $(\mathrm{M}=4.28 ; \mathrm{SD}=2.22)$ compared to medium $(\mathrm{M}=2.72$; $\mathrm{SD}=2.65)$ and low hypnotizables $(\mathrm{M}=2.41 ; \mathrm{SD}=2.34)$ independently of the condition. ${ }^{42}$

\section{Chronic Pain}

A case report indicated that VRH combined with daily hypnosis exercises allowed a reduction of $36 \%$ of pain intensity and $33 \%$ pain unpleasantness in a chronic neuropathic pain patient over the course of 33 VRH sessions. ${ }^{41}$ This decrease in pain intensity after VRH intervention was also observed in a patient with pain associated with gluteal hidradenitis in two days ( $62 \%$ drop) ${ }^{48}$

\section{Other Outcomes}

\section{Medication Use}

Three studies measured the level of opioids required for patients before, during, and after the VRH treatment. Among these, two studies used one VRH session per day for two days. ${ }^{45,49}$ One study used VRH on day 1 and hypnosis alone on day $2 .{ }^{38}$ During these two treatment days, 13 burn injured patients needed $50 \%$ less opioids than usual during and after wound care. ${ }^{49}$ By contrast, three patients who suffered from pain associated with multiple fracture trauma did not have any modification in the amount of opioids given by the medical team. ${ }^{45}$ In one study, medication levels decreased substantially 
for one patient from baseline to day 2 but increased again on day 3 when there was no $\mathrm{VRH}^{38}$

\section{Sense of Presence}

A randomized study on 120 volunteers showed that, independent of the degree of hypnotizability, there is an effect of treatment on emotional involvement, as measured with the 36 -items presence and reality judgment questionnaire. ${ }^{43,50}$ VRH subjects were more emotionally involved in the virtual world and their sense of presence was more intense (mean score: 78) than subjects who received VR with no hypnotic suggestion (mean score: 65 ). ${ }^{43}$

\section{Anxiety}

Five studies measured the level of anxiety before and after the treatment with a graphic rating scale (GRS), ${ }^{38,45,48}$ or the burn specific pain anxiety scale (BSPAS). ${ }^{49,51}$ There was an immediate decrease in anxiety from before to after VRH of around $100 \%$ on day 1 in 3 patients. ${ }^{45}$ Anxiety reported by a chronic pain patient decreased by $50 \%$ on day 1 , and $100 \%$ on day 2 after VRH application, ${ }^{48}$ and a $50 \%$ drop in anxiety was reported in a severely burn patient on day $1 .{ }^{38}$ Anxiety dropped by a mean of $26 \%$ after VRH sessions in 13 burn patients. ${ }^{49}$

\section{Discussion}

Studies have shown the interest in hypnosis, VR, and VRH to modulate pain perception and unpleasantness. Interestingly, results highlight differences in pain reduction depending on the techniques used and levels of the patient's suggestibility to hypnosis. According to Enea et al (2014), we note that highly hypnotizable subjects reported less pain when using hypnotic tools (hypnosis and VRH), while low hypnotizable subjects reported less pain when using VR and VRH than hypnosis alone or no treatment. $^{43}$ In addition, it seems that post-hypnotic analgesia is dependent of the hypnotizability level to reduce pain intensity, whereas VR is not. ${ }^{42}$ Regarding these results, we could argue that VR and hypnosis involve different mechanisms for pain reduction. VRH increased the patients' short-term quality of life, although the pain reduction effects were not persistent beyond a month after the end of the treatment, ${ }^{41}$ compared to hypnosis which has already shown increases in quality of life over a long period. ${ }^{16} \mathrm{VR}$ pain modulation could be due to distraction mechanisms inherent to the VR environment (and not related to hypnotizability level), while response to hypnosis suggestions results from the suggestibility capacities of subjects (ie, tendency to comply with instructions and a relative suspension of critical judgment). ${ }^{52}$ In these eight studies, VR is used in an attempt to facilitate the hypnotic induction process for the patient, without the intervention of a trained hypnotherapist. Globally, VRH has positive effects on pain and anxiety and did not add supplementary time to the wound care, did not provoke nausea or motion sickness in these studies, and most of the patients enjoyed the experience. ${ }^{49}$ However, in light of the results presented in this review, we cannot affirm that VR makes hypnosis easier for patients. Askay et al (2009) suggested that VR would not inhibit the hypnotic process and may even facilitate it by employing visual imagery, ${ }^{39}$ but there is a need for concrete additional results. More studies are required to investigate the possible additional effect of VR to hypnosis. Promising results are shown regarding decrease of pain levels and the amount of medication reduction when using a VRH display. The fact that opioids can be reduced by $50 \%$ in some cases and by $0 \%$ in others partly can be explained because the use of medication depends on the team's care procedure and doctor's decisions and not the investigator's study. ${ }^{45}$ Prospective randomized studies are needed to investigate the capacity of non-pharmacological techniques to reduce the amount of medication given to the patient, depending on the pathology, and to investigate the short and long term effects of VRH on medication use.

\section{Limitations and Future Directions}

This review aimed to understand the ability of VRH to reduce pain. The literature on this subject is relatively scarce. Two studies used a large sample of participants and found interesting tendency for pain reduction. ${ }^{42,43}$ Nevertheless, in these studies, pain was artificially administered to healthy participants and no clinical research has yet tested a large sample of patients. In this review, we included five clinical case reports that are limited in their extent of clinical application. Besides, studies design showed different ways to use VRH: either by giving hypnosis alone to individuals and then VR, or the opposite, or the combined version of giving both at once. There is no single method to use hypnosis with VR. Each experiment has its own protocol with variations in the time of exposure to therapy, the study design, and the hypnotic suggestions according to the study conducted, which makes them difficult to compare. The number of sessions also varied according to the study. Generally, the amount of VRH 
sessions is limited. In three studies, only one VRH session was given to the patients. Only one study used VRH as a quotidian long-term technique over 6 months. All these studies can give us paths to follow but, as a result of the limited score, it would be difficult to make strong conclusions about the best way to use VRH. One strong asset of these studies is that all used "SnowWorld" movie which allows to compare their effect on pain reduction without assigning these results to the different VR environments. Regarding assessments, to a fundamental level, it is surprising to note that while hypnotizability has already been studied (although in a limited number of studies), immersion and sense of presence were of less interest. Immersion and sense of presence are two essential notions of VR displays. ${ }^{53}$ In this review, only one study on pain modulation measured the sense of presence ${ }^{43}$ and none investigated the level of immersion. A great advancement in the field of psychosocial approaches would be to see whether objective and subjective immersion and sense of presence might have the same effect in VRH as in VR for pain management. To our knowledge, phenomenological and clinical comparisons of VR, VRH, and hypnosis has not yet been investigated. Randomized comparative studies on hypnosis, VR, and VRH are required to reveal parallels and divergences between all the techniques and their cognitive fundamental concepts.

\section{Conclusion}

Over the last few years, non-pharmacological approaches have been generating interest from people and healthcare teams. Techniques like hypnosis and VR are being investigated in numerous studies and present a different way to perceive medical advances. This scoping review underlines the importance of hypnosis, VR, and VRH to reduce pain in patients and healthy volunteers. Although VR pain distraction is now well-documented and commonly used in commercial, scientific, and clinical fields; VRH is far from being as widespread as the distractive version of VR reported in the literature. This scoping review showed that a few studies investigated VRH for modulation of pain. On the 8 studies, 6 are clinical studies and 2 are randomized controlled trials on healthy subjects. Only these two have a large sample $(\mathrm{n}=120, \mathrm{n}=103), 5$ are clinical study cases or case series from 1 to 13 patients and one is prospective randomized on 20 patients. Among these 8 studies, heterogeneous results on pain were found: globally, results showed that all three techniques (VR, hypnosis and $\mathrm{VRH}$ ) are able to reduce pain. However, positive results are not consistent for all patients all the days and we cannot affirm that VR added value to hypnosis when they are combined. It is now necessary to elaborate additional randomized and controlled research paradigms in order to understand the effects on the subject's phenomenology, cognition, perception and clinical application. Randomized studies that compare these nonpharmacological techniques to each other are very uncommon and would help to define the best practices for the use of VRH techniques in clinical medicine and management of pain.

\section{Abbreviations}

3D, Three Dimensions; BSPAS, Burn Specific Pain Anxiety Scale; GRS, Graphic Rating Scale (0-100); HGSHS Form A, Harvard Group Scale of Hypnotic Susceptibility; NRS, Numeric Rating Scale (0-10); PRJQ, Presence and Reality Judgement Questionnaire (36 items); SCHCS, Stanford Hypnotic Clinical Scale; TAS, Tellegen Absorption Scale; VDS, Verbal Descriptor Scale (6 descriptors); VR, Virtual Reality; VRH, Virtual Reality Hypnosis.

\section{Acknowledgments}

The study was supported by the University and University Hospital of Liège, "Plan National Cancer" of Belgium (grant number 138), Benoit Foundation (Bruxelles), the French Speaking Community Concerted Research Action (ARC 06/11 - 340), the Belgian National Funds for Scientific Research (FRS-FNRS), Human Brain Project (EU-H2020fetflagshiphbp-sgal-ga720270), the Luminous project (EUH2020-fetopen-ga686764), Wallonie-Bruxelles International, the James McDonnell Foundation, Mind Science Foundation, IAP research network P7/06 of the Belgian Government (Belgian Science Policy), the European Commission, the Public Utility Foundation "Université Européenne du Travail," "Fondazione Europea di Ricerca Biomedica," and the Bial Foundation. Steven Laureys is research director at FRS-FNRS.

\section{Disclosure}

Marie-Elisabeth Faymonville is part of a scientific board of Oncomfort society. The authors report no other conflicts of interest in this work.

\section{References}

1. Morley S, Williams A, Eccleston C. Examining the evidence about psychological treatments for chronic pain: time for a paradigm shift? Pain. 2013;154(10):1929-1931. doi:10.1016/j.pain.2013.05.049 
2. Dixon KE, Keefe FJ, Scipio CD, Perri LM, Abernethy AP. Psychological interventions for arthritis pain management in adults: a meta-analysis. Health Psychol. 2007;26(3):241-250. doi:10.1037/ 0278-6133.26.3.241

3. Veehof MM, Oskam M-J, Schreurs KMG, Bohlmeijer ET. Acceptance-based interventions for the treatment of chronic pain: a systematic review and meta-analysis. Pain. 2011;152(3):533-542. doi:10.1016/j.pain.2010.11.002

4. Vanhaudenhuyse A, Boly M, Balteau E, et al. Pain and non-pain processing during hypnosis: a thulium-YAG event-related fMRI study. NeuroImage. 2009;47(3):1047-1054. doi:10.1016/j.neuroimage.2009. 05.031

5. Pourmand A, Davis S, Lee D, Barber S, Sikka N. Emerging utility of virtual reality as a multidisciplinary tool in clinical medicine. Games Health J. 2017;6(5):263-270. doi:10.1089/g4h.2017.0046

6. Bonica JJ. The need of a taxonomy. Pain. 1979;6(3):247-248. doi:10.1016/0304-3959(79)90046-0

7. Price DD, Milling LS, Kirsch I, Duff A, Montgomery GH, Nicholls SS. An analysis of factors that contribute to the magnitude of placebo analgesia in an experimental paradigm. Pain. 1999;83 (2):147-156. doi:10.1016/S0304-3959(99)00081-0

8. Wall PD. The placebo effect: an unpopular topic. Pain. 1992;51 (1):1-3. doi:10.1016/0304-3959(92)90002-S

9. Melzack R, Wall PD. Pain mechanisms: a new theory. Science. 1965;150(3699):971-979. doi:10.1126/science.150.3699.971

10. Jones AK, Brown WD, Friston KJ, Qi LY, Frackowiak RS. Cortical and subcortical localization of response to pain in man using positron emission tomography. Proc Biol Sci. 1991;244(1309):39-44. doi:10.1098/rspb.1991.0048

11. Peyron R, Laurent B, García-Larrea L. Functional imaging of brain responses to pain. A review and meta-analysis. Neurophysiol Clin. 2000;30(5):263-288. doi:10.1016/S0987-7053(00)00227-6

12. Bourne S, Machado AG, Nagel SJ. Basic anatomy and physiology of pain pathways. Neurosurg Clin N Am. 2014;25(4):629-638. doi:10.1016/j.nec.2014.06.001

13. Gewandter JS, Dworkin RH, Turk DC, et al. Research design considerations for chronic pain prevention clinical trials: IMMPACT recommendations. Pain. 2015;156(7):1184-1197. doi:10.1097/j. pain.0000000000000191

14. Chlan LL, Weinert CR, Heiderscheit A, et al. Effects of patient-directed music intervention on anxiety and sedative exposure in critically ill patients receiving mechanical ventilatory support: a randomized clinical trial JAMA. 2013;309(22):2335. doi:10.1001/jama.2013.5670

15. Zeidan F, Vago DR. Mindfulness meditation-based pain relief: a mechanistic account. Ann N Y Acad Sci. 2016;1373(1):114-127. doi:10.1111/nyas. 13153

16. Vanhaudenhuyse A, Gillet A, Malaise N, et al. Efficacy and cost-effectiveness: a study of different treatment approaches in a tertiary pain centre. Eur J Pain Lond Engl. 2015;19 (10):1437-1446. doi:10.1002/ejp.674

17. Vanhaudenhuyse A, Gillet A, Malaise N, et al. Psychological interventions influence patients' attitudes and beliefs about their chronic pain. J Tradit Complement Med. 2018;8(2):296-302. doi:10.1016/j. jtcme.2016.09.001

18. Elkins GR, Barabasz AF, Council JR, Spiegel D. Advancing research and practice: the revised APA division 30 definition of hypnosis. Am J Clin Hypn. 2015;57(4):378-385. doi:10.1080/00029157.2015.1011465

19. Fisch S, Brinkhaus B, Teut M. Hypnosis in patients with perceived stress - a systematic review. BMC Complement Altern Med. 2017;17 (1). doi:10.1186/s12906-017-1806-0

20. McBride JJ, Vlieger AM, Anbar RD. Hypnosis in paediatric respiratory medicine. Paediatr Respir Rev. 2014;15(1):82-85. doi:10.1016/j. prrv.2013.09.002

21. Esdaile J. Mesmerism in India, and Its Practical Application in Surgery and Medicine. London: Longman, Brown, Green, and Longmans; 1846.
22. Vanhaudenhuyse A, Laureys S, Faymonville M-E. Neurophysiology of hypnosis. Clin Neurophysiol. 2014;44(4):343-353. doi:10.1016/j. neucli.2013.09.006

23. Defechereux T, Degauque C, Fumal I, et al. L'hypnosédation, un nouveau mode d'anesthésie pour la chirurgie endocrinienne cervicale. Étude prospective randomisée. Ann Chir. 2000;125(6):539-546. doi:10.1016/S0003-3944(00)00238-8

24. Rousseaux F, Faymonville M-E, Nyssen A-S, Grégoire C, Bicego A, Vanhaudenhuyse A. Hypnose et recherche : que se passe-t-il à Liège ? HEGEL. 2018;(03). doi:10.4267/2042/68730. French.

25. Faymonville M-E, Fissette J, Mambourg PH, Delchambre A, Lamy M. Hypnose, hypnosédation. Conceptions actuelles et leurs applications en chirurgie plastique. Rev Médicale Liège. 1994;49(1):13-22.

26. Grégoire C, Bragard I, Jerusalem G, et al. Group interventions to reduce emotional distress and fatigue in breast cancer patients: a 9-month follow-up pragmatic trial. $B r \quad J$ Cancer. 2017;117 (10):1442-1449. doi:10.1038/bjc.2017.326

27. Bragard I, Etienne A-M, Faymonville M-E, et al. A nonrandomized comparison study of self-hypnosis, yoga, and cognitive-behavioral therapy to reduce emotional distress in breast cancer patients. Int J Clin Exp Hypn. 2017;65(2):189-209. doi:10.1080/002071 44.2017.1276363

28. Grégoire C, Nicolas H, Bragard I, et al. Efficacy of a hypnosis-based intervention to improve well-being during cancer: a comparison between prostate and breast cancer patients. BMC Cancer. 2018;18 (1):677. doi:10.1186/s12885-018-4607-z

29. Virtual Reality, n. [homepage on internet]. OED Online. Oxford University Press. Available from: https://www.oed.com/view/Entry/ 328583. Accessed September 18, 2019.

30. Rizzo AS, Koenig ST. Is clinical virtual reality ready for primetime? Neuropsychol. 2017;31(8):877-899. doi:10.1037/neu0000405

31. Kenney MP, Milling LS. The effectiveness of virtual reality distraction for reducing pain: a meta-analysis. Psychol Conscious Theory Res Pract. 2016;3(3):199-210. doi:10.1037/cns0000084

32. Wiederhold BK, Gao K, Sulea C, Wiederhold MD. Virtual reality as a distraction technique in chronic pain patients. Cyberpsychol Behav Soc Netw. 2014;17(6):346-352. doi:10.1089/cyber.2014.0207

33. Garrett B, Taverner T, Gromala D, Tao G, Cordingley E, Sun C. Virtual reality clinical research: promises and challenges. JMIR Serious Games. 2018;6(4):e10839. doi:10.2196/10839

34. Ramachandran VS, Seckel EL. Using mirror visual feedback and virtual reality to treat fibromyalgia. Med Hypotheses. 2010;75 (6):495-496. doi:10.1016/j.mehy.2010.07.003

35. Garrett B, Taverner T, McDade P. Virtual reality as an adjunct home therapy in chronic pain management: an exploratory study. JMIR Med Inform. 2017;5(2):e11. doi:10.2196/medinform.7271

36. Patterson DR, Jensen MP, Wiechman SA, Sharar SR. Virtual reality hypnosis for pain associated with recovery from physical trauma. Int J Clin Exp Hypn. 2010;58(3):288-300. doi:10.1080/00207141 003760595

37. Grant CD, Nash MR. The computer-assisted hypnosis scale: standardization and norming of a computer-administered measure of hypnotic ability. Psychol Assess. 1995;7(1):49-58. doi:10.1037/1040-3590.7.1.49

38. Patterson DR, Tininenko JR, Schmidt AE, Sharar SR. Virtual reality hypnosis: a case report. Int J Clin Exp Hypn. 2004;52(1):27-38. doi:10.1076/iceh.52.1.27.23925

39. Askay SW, Patterson DR, Sharar SR. Virtual reality hypnosis. Contemp Hypn. 2009;26(1):40-47. doi:10.1002/ch.371

40. Hoffman HG, Garcia-Palacios A, Patterson DR, Jensen M, Furness T, Ammons WF. The effectiveness of virtual reality for dental pain control: a case study. Cyberpsychol Behav. 2001;4(4):527-535. doi:10.1089/109493101750527088

41. Oneal BJ, Patterson DR, Soltani M, Teeley A, Jensen MP. Virtual reality hypnosis in the treatment of chronic neuropathic pain: a case report. Int J Clin Exp Hypn. 2008;56(4):451-462. doi:10.1080/ 00207140802255534 
42. Patterson DR, Hoffman HG, Palacios AG, Jensen MJ. Analgesic effects of posthypnotic suggestions and virtual reality distraction on thermal pain. J Abnorm Psychol. 2006;115(4):834-841. doi:10.1037/ 0021-843X.115.4.834

43. Enea V, Dafinoiu I, Opriş D, David D. Effects of hypnotic analgesia and virtual reality on the reduction of experimental pain among high and low hypnotizables. Int J Clin Exp Hypn. 2014;62(3):360-377. doi:10.1080/00207144.2014.901087

44. Scott J, Huskisson E. Graphic representation of pain. Pain. 1976;2 (2):175-184. doi:10.1016/0304-3959(76)90113-5

45. Teeley AM, Soltani M, Wiechman SA, Jensen MP, Sharar SR, Patterson DR. Virtual reality hypnosis pain control in the treatment of multiple fractures: a case series. Am J Clin Hypn. 2012;54 (3):184-194. doi:10.1080/00029157.2011.619593

46. Gamsa A. The role of psychological factors in chronic pain. A half century of study. Pain. 1994;57(1):5-15. doi:10.1016/0304-3959(94) 90103-1

47. Gracely RH, McGrath F, Dubner R. Ratio scales of sensory and affective verbal pain descriptors. Pain. 1978;5(1):5-18. doi:10.1016/0304-3959(78)90020-9

48. Soltani M, Teeley AM, Wiechman SA, Jensen MP, Sharar SR, Patterson DR. Virtual reality hypnosis for pain control in a patient with gluteal hidradenitis: a case report. Contemp Hypn Integr Ther. 2012;28(2):142-147. doi:10.1080/00029157.2011.619593

49. Patterson DR, Wiechman SA, Jensen M, Sharar SR. Hypnosis delivered through immersive virtual reality for burn pain: a clinical case series. Int J Clin Exp Hypn. 2006;54(2):130-142. doi:10.1080/ 00207140500528182
50. Baños RM, Botella C, García-Palacios A, Martín HV, Perpiñá C, Raya MA. Presence and reality judgment in virtual environments: a unitary construct? Cyberpsy Behav Soc Netw. 2000;3:327-335. doi:10.1089/10949310050078760

51. Taal LA, Faber AW. The burn specific pain anxiety scale: introduction of a reliable and valid measure. Burns. 1997;23(2):147-150. doi:10.1016/S0305-4179(96)00117-9

52. Spiegel D. Neurophysiological correlates of hypnosis and dissociation. J Neuropsychiatry Clin Neurosci. 1991;3(4):440-445. doi:10.1176/jnp.3.4.440

53. Slater M, Wilbur S. A framework for immersive virtual environments (five): speculations on the role of presence in virtual environments. Presence Teleop Virt Environ. 1997;6(6):603-616. doi:10.1162/ pres.1997.6.6.603

54. Shor RE, Orne EC. Norms on the Harvard group scale of hypnotic susceptibility, form A. Int J Clin Exp Hypn. 1963;11(1):39-47. doi:10.1080/00207146308409226

55. Hilgard ER. The stanford hypnotic susceptibility scales as related to other measures of hypnotic responsiveness. Am J Clin Hypn. 1978;21 (2-3):68-83. doi:10.1080/00029157.1978.10403965

56. Tellegen A, Atkinson G. Openness to absorbing and self-altering experiences ("absorption"), a trait related to hypnotic susceptibility. J. Abnorm. Psychol. 1974;83:268-277. doi:10.1037/h0036681
Journal of Pain Research

\section{Publish your work in this journal}

The Journal of Pain Research is an international, peer reviewed, open access, online journal that welcomes laboratory and clinical findings in the fields of pain research and the prevention and management of pain. Original research, reviews, symposium reports, hypothesis formation and commentaries are all considered for publication. The manuscript

\section{Dovepress}

management system is completely online and includes a very quick and fair peer-review system, which is all easy to use. Visit http:// www.dovepress.com/testimonials.php to read real quotes from published authors. 